\title{
Main changes made to Part E-Resistance to the passage of sound
}

Received (in revised form): 27th September, 2004

\section{Les Fothergill $\mathrm{PhD}$}

has worked in the Buildings Division of the Office of the Deputy Prime Minister (ODPM) (and its predecessors) for ten years. He is responsible for four parts of the Building Regulations: Part E - Resistance to the passage of sound; Part F - Ventilation; Part K - Protection from falling, "collision and impact; Part N - Glazing - safety in relation to impact, opening and cleaning. Before joining ODPM he worked at the Building Research Establishment (BRE) and was Head of the Acoustics Section. He has contributed to several British and CEN Standards and has written many BRE and journal papers. Before joining BRE he worked in the aircraft industry.

\begin{abstract}
Major changes to Part E of the Building Regulations were introduced on 1st July, 2003 and further changes came into force on 1st July, 2004. This paper summarises the main features of these changes.
\end{abstract}

\section{Keywords:}

sound insulation, building regulations, Part E, pre-completion testing, robust details

\section{INTRODUCTION}

The review of Part E was carried out in response to complaints about poor sound insulation and Building Research Establishment surveys which indicated that about 25 per cent of separating walls and 40 per cent of separating floors were failing to meet the standards intended in the 1992 edition of Part E. The policy of encouraging higher density housing was thought likely to make the situation worse unless action was taken. The aims of the review were to improve standards, improve compliance with the standards and to extend the scope of the requirements to improve the acoustic conditions in dwellings and schools.

\section{NEW REQUIREMENTS}

The 1992 functional Requirements E1 to E3 dealt with the airborne sound

Les Fothergill Buildings Division

Office of the Deputy Prime Minister 18/A Portland House, Stag Place London SW1E $5 \mathrm{LP}$, UK

Tel: +44 (o) 2079445737

E-mail: les.fothergill@odpm.gsi.gov.uk insulation of separating walls and the airborne and impact sound insulation of separating floors. The Requirements only applied to attached houses and self-contained flats. The 1992 Requirements have now been incorporated into the new E1, and the new E2 to E4 extend the scope of Part E into areas of acoustics that have not previously been controlled. 


\section{Requirement E1}

\section{Sound from other parts of the building}

Pre-completion testing
The titles of the four new Requirements are as follows, and they are discussed in turn below:

E1: Protection against sound from other parts of the building and adjoining buildings.

E2: Protection against sound within a dwelling house etc.

E3: Reverberation in the common internal parts of buildings containing flats or rooms for residential purposes.

E4: Acoustic conditions in schools.

For full details the reader should refer to Approved Document E 2003 and Amendments 2004 to Approved Document E 2003 (ODPM, 2003 and 2004). The Approved Documents give guidance on how the Requirements can be satisfied in common situations, but the guidance is not exhaustive.

\section{Requirement E1}

Requirement E1 applies to houses and flats as before, and also a new category of dwelling called 'rooms for residential purposes'. This

category includes hotel bedrooms and hostel types of accommodation, but excludes accommodation where the occupants are patients and unable to lead independent lives. Such accommodation would be found in hospitals and care homes that provide 'personal care' as defined in the Care Standards Act (2000).

The Requirement asks for reasonable resistance to sound from the other parts of the same building and from adjoining buildings; however, the guidance in Section 0 of Approved Document E 2003 (ODPM, 2003) gives numerical performance standards to illustrate the meaning of reasonable for different types of dwelling. The performance standards are set out in Tables 1a and 1b of Approved Document E 2003 (ODPM, 2003), and cover houses/flats and rooms for residential purposes, both new and formed by material change of use (conversion) of other buildings.

The introduction of clear performance standards makes enforcement more practical, and for this purpose pre-completion testing (PCT) was introduced from 1st July, 2003 for dwellings (including rooms for residential purposes) formed by material change of use and new rooms for residential purposes. The introduction of PCT for new houses and flats was delayed until 1st July, 2004 for reasons explained below under Robust details.

\section{Pre-completion testing}

There are many reasons why separating walls and floors may provide poor sound insulation. Perhaps the most obvious are workmanship faults such as oversized holes for services that may result in air-paths through the structure. Less obvious faults may be attributable to poor design, for example, where a designer has failed to specify fully an important flanking detail, or has specified a timber separating floor in 
conjunction with lightweight concrete flanking walls without adequate linings.

Because of the difficulty of detecting all such defects in the normal course of building control inspections, the Office of the Deputy Prime Minister (ODPM) introduced pre-completion testing (PCT) a system for measuring the sound insulation of a sample of new dwellings on each site. New Building Regulations 20A for local authorities and 12A for approved inspectors provided power for building control bodies to ask a builder to have appropriate sound insulation tests carried out on a sample of dwellings on each site. If a test is failed, then remedial treatment is required, as is investigation of other rooms in the same dwelling and also other dwellings that have been built to the same design but not tested. The building control body should consider a builder's completion plan and ask for specific dwellings to be tested. The suggested procedure is set out in Section 1 of Approved Document E 2003 (ODPM, 2003).

The Regulations ask for 'appropriate sound insulation testing' to be carried out. This will normally mean a procedure in accordance with Section 1 and Annex B of Approved Document E 2003 (ODPM, 2003). For minor works, however, such as converting a room in a house for bed and breakfast use, the building control body may consider a simpler test to be appropriate-for example, listening to a radio or television played at a reasonably high level in an adjoining room. If this test is failed then either remedial work could be required or a standard test could be carried out to establish the actual performance.

To ensure that test results are reliable, it is important that full sound insulation tests are carried out by competent organisations following the appropriate British/European standards and using suitable equipment with traceable calibrations. ODPM strongly recommends that test organisations should be United Kingdom Accreditation Service (UKAS) accredited or be members of the Association of Noise Control registration scheme. Such organisations are listed on their respective websites: www.ukas.org and www.association-of-noise-consultants.co.uk/index.htm.

Sound insulation tests require access to both sides of the separating wall or floor. Therefore, if work on a separating wall or floor that would normally be subjected to a test is carried out in a property adjoining an occupied property, it is necessary to have the occupier's permission before a test can be carried out. As test organisations do not have a right of access to occupied property, the test cannot be carried out if permission is withheld. Instead, the building control body may think it is appropriate to carry out additional site checks to ensure the design has been implemented properly.

Robust details

\section{Robust details}

A disadvantage of testing is that it cannot be undertaken until the dwelling is practically complete and ready for occupation. If a test is failed, the necessary remedial works could cause significant delays to 
the handover, with obvious implications for the new occupants and the builder.

The House Builders Federation (HBF) accepted that there was a need to improve sound insulation, but felt there should be a more practical alternative to testing. The HBF suggested that builders would rather spend money on building better constructions than testing more traditional designs, and volunteered to develop robust details. These would be highperformance constructions with reasonable workmanship tolerance, which could be expected to satisfy the performance standards without the need for checking by regular tests. Although there was some doubt about the feasibility of achieving workmanship tolerance, after much discussion, the Building Regulations Advisory Committee (BRAC) eventually recommended that Ministers should agree to the development and testing of robust details and to consider the results of the test programme. The testing regime and performance required for robust details were agreed with ODPM.

The HBF carried out an intensive development programme and ODPM put the resulting proposed robust details designs out for public consultation between August and November 2003. A good spread of building professionals responded to the public consultation, and the majority supported the proposals. After further consideration BRAC recommended accepting robust details as an alternative to testing for a trial period of three years, and Phil Hope, the Minister responsible for Building Regulations, made an announcement to this effect in January 2004.

A new company, Robust Details Ltd, has been started by the HBF to run the new system. The company has independent directors who represent different sectors of the industry (including building control) and ODPM has observer status on the board. More information about the company and system is on the website: www.robustdetails.com.

The new company has two main functions. First, it will continue to assess candidates for robust details status, according to the rules already agreed with ODPM. As well as assessing additional generic forms of construction, it could also consider proprietary separating wall and floor systems. Secondly, it will monitor the performance of a sample of the robust details as built in the field through inspection and testing, and inform building control of any failures so they can take enforcement action to have the performance improved. ODPM sees this monitoring as a vital part of the new system as it will give a good idea of how well individual constructions are performing and show if standards are being maintained. Any constructions that are found not to perform as well as expected will be re-engineered or withdrawn from the robust details handbook.

For monitoring to work, Robust Details Ltd must know where these details are being used. For this purpose, Regulations 20A and 12A have been amended to require builders to notify building control about where they intend to use robust details, the details they intend to use, and to include a unique number supplied by Robust Details Ltd for each dwelling they intend to build. These unique numbers can only be 
obtained from Robust Details Ltd by registering the intended use of the details, so that the address and types of detail can be recorded in a database from which the sample to be inspected or tested can be drawn. Robust Details Ltd requires a fee for registration, which is used to maintain the system.

Use of robust details is an alternative to PCT to show compliance with Requirement E1. Robust details are not deemed to satisfy the Requirement and enforcement action can be taken if tests, made for any reason, show that the performance standards have not been met.

The robust details scheme is not a self-certification scheme, so building control bodies should still carry out site inspections in the normal way. From the building control body's point of view, the main difference when assessing an application to use robust details is the need to check that the notification includes the required unique number for each dwelling. If it does not, then either the builder should obtain the unique numbers or the site should be subject to PCT.

Robust Details Ltd issues builders with checklists for each construction and a compliance certificate on which the builder can confirm that he has followed the robust details specifications properly. This compliance certificate is not a self-certification certificate, but asking for a copy may give building control bodies more confidence when they issue completion/final certificates.

The robust details system represents a new way of working, with the industry developing the details and monitoring their performance, but with building control providing third-party checks. This is different from the Fenestration Self-Assessment Scheme (FENSA) for replacement windows as FENSA provides for self-certification.

\section{Requirement E2}

\section{Sound within a dwellings}

\section{Requirement E2}

Requirement E2 sets standards for sound insulation between most rooms within a dwelling, and it applies to both attached and detached dwellings. The walls controlled are those between bedrooms and other rooms, and those between a room containing a WC and other rooms. All new internal floors are controlled. There are three important exclusions: an internal wall that contains a door, an internal wall which separates an en-suite toilet from the associated bedroom, and existing internal walls and floors in a building which is subject to a material change of use.

The performance standard is the same for walls and floors, and has been set at $R_{\mathrm{w}} 40 \mathrm{~dB} . R_{\mathrm{w}}$ is an index used for laboratory measurements, and the intention is that walls and floors should be used that are either described in the Approved Document or are proprietary systems that have been tested in a laboratory and been shown to meet the performance standard.

For internal floors, only insulation against airborne sound is controlled because it was considered too onerous to control insulation against impact sound as well. It is not intended that the performance of internal walls and floors should be verified by testing on site, but by the use of correctly specified details and good construction. 


\section{Requirement $\mathrm{E}_{3}$}

Reverberation

\section{Requirement E4}

\section{Schools}

\section{Requirement $\mathrm{E}_{3}$}

The purpose of this requirement is to reduce the reverberation of noise produced in the common parts of blocks of flats and rooms for residential purposes to minimise the disturbance caused to other residents in the building. The guidance in Approved Document E 2003 (ODPM, 2003) offers two methods of calculating the amount of absorption required to control reverberant sound. Method A is very simple, and just entails using ceiling tiles of specified characteristics, but it can lead to over-design. Method B takes account of the absorption of all the surfaces in the space (including any carpet) so is more accurate, but is more complicated to use.

The Requirement only applies to corridors, stairwells, hallways and entrance halls which give access to the flat or room for residential purposes. This means that common parts that are not adjoining the flats or rooms for residential purposes need not be treated.

\section{Requirement $\mathrm{E}_{4}$}

This new requirement brings the acoustic conditions in teaching and learning spaces in schools under the Building Regulations for the first time. Because the design of schools is complex, a separate guidance document, Building Bulletin 93 (BB 93), has been prepared by the Department for Education and Skills (2003).

The performance standards are set out in Section 1 of BB 93. They include: maximum indoor ambient noise levels (in the absence of pupils); airborne sound insulation between spaces; airborne sound insulation between spaces and circulation spaces; impact sound insulation of floors; and reverberation in teaching and study spaces (as reverberation affects speech intelligibility). Section 1 also includes guidance on demonstrating compliance with the building control body, with an example submission in Appendix 10 of BB 93. PCT does not apply as a means of demonstrating compliance with E4 for Building Regulations purposes, although BB 93 does recommend that the client includes performance testing in the contract with the builder. The other sections in BB 93 give valuable guidance on the design of schools to satisfy the acoustic performance standards (Department for Education and Skills, 2003).

\section{CONCLUSION}

The new Part E contains a package of measures intended to improve the acoustic conditions in dwellings and schools. The effectiveness of the measures will be monitored and any changes found necessary will be made in the next revision.

(C) Crown copyright 2005

\section{References}

Department for Education and Skills (2003) Acoustic Design of Schools, Building Bulletin 93, available from the Stationery Office, ISBN 0-11-271105-7, available free of charge on the DfES website: http://www.teachernet.gov.uk/acoustics. 
ODPM (2003) Approved Document E 2003, Resistance to the Passage of Sound, available from the Stationery Office, ISBN 0-11-753642-3, available free of charge on the ODPM website: www.odpm.gov.uk.

ODPM (2004) Amendments 2004 to Approved Document E 2003, available from the Stationery Office, ISBN 0-11-753915-5, available free of charge on the ODPM website: www.odpm.gov.uk. 